J-SANAK: Jurnal Kajian Anak

(p-ISSN: 2686-5343 le-ISSN: 2715-7989)

Vol. (1) (2), (Januari - Juni) (2019), (Halaman)(1-14)

DOI: https://doi.org/10.24127/j-sanak.v1i02.126

\title{
EFEKTIVITAS METODE TANYA JAWAB DALAM MENGEMBANGKAN BAHASA ANAK USIA DINI DI RAUDHATUL ATHFAL ISMARIA RAJABASA BANDAR LAMPUNG
}

\author{
Epi Tamala \\ Universitas Islam Negeri Raden Intan Lampung \\ Epiginda04@gmail.com
}

\begin{abstract}
ABSTRAK
Bahasa merupakan salah satu aspek kemampuan dasar yang harus dikembangkan pada jenjang pendidikan di Taman Kanak-kanak. Melalui bahasa anak dapat mengenal dan memahami dirinya, sesama, dan lingkungan hidupnya. Namun perkembangan bahasa anak di Raudhatul Athfal Ismaria Rajabasa Bandar Lampung masih kurang atau belum berkembang dengan baik khususnya pada kelas B6. Maka metode tanya jawab merupakan salah satu metode yang digunakan oleh guru dalam mengembangkan bahasa anak usia dini di Raudhatul Athfal Ismaria Rajabasa Bandar Lampung. Dengan demikian penulis merumuskan judul penelitian efektivitas metode tanya jawab dalam mengembangkan bahasa anak usia dini di Raudhatul Athfal Ismaria Rajabasa Bandar Lampung.

Adapun rumusan masalah dalam penelitian ini adalah "bagaimana efektivitas metode tanya jawab dalam mengembangkan bahasa anak usia dini di Raudhatul Athfal Ismaria Rajabasa Bandar Lampung?". Tujuan penelitian ini adalah untuk mengetahui efektivitas metode tanya jawab dalam mengembangkan bahasa anak usia dini di Raudhatul Athfal Ismaria Rajabasa Bandar Lampung. Dalam penelitian ini penulis menggunakan jenis penelitian deskriptif kualitatif. Teknik pengumpulan data yang penulis gunakan adalah observasi, wawancara, dan dokumentasi.

Langkah-langkah metode tanya jawab yang telah diterapkan oleh guru dalam mengembangkan bahasa anak usia dini di Raudhatul Athfal Ismaria Rajabasa Bandar Lampung antara lain: Tahap persiapan tanya jawab, tahap awal tanya jawab, tahap pengembangan tanya jawab, tahap akhir tanya jawab. Dengan menerapkan langkah-langkah metode tanya jawab di Raudhatul Athfal Ismaria Rajabasa Bandar Lampung maka perkembangan bahasa anak dapat berkembang dengan baik.

Berdasarkan hasil analisa tersebut, dapat disimpulkan bahwa metode tanya jawab telah dilakukan dengan langkah yang baik dan efektif dalam mengembangkan bahasa anak usia dini.
\end{abstract}

Kata kunci : Metode tanya jawab, bahasa anak usia dini

Received 28-02-2020; Received in revised form 18-04-2020; Accepted 18-04-2020.

Copyright (C) 2020, Universitas Muhammadiyah Metro| 1 
J-SANAK: Jurnal Kajian Anak

(p-ISSN: 2686-5343 le-ISSN: 2715-7989)

Vol. (1) (2), (Januari - Juni) (2019), (Halaman)(1-14)

DOI: https://doi.org/10.24127/j-sanak.v1i02.126

\begin{abstract}
Language is one aspect of basic skills that must be developed at the level of education in kindergarten. Through language children can know and understand themselves, others, and their environment. However, children's language development at kindergarten Ismaria Rajabasa Bandar Lampung is still lacking or not well developed, especially in class B6. Then the question and answer method is one of the methods used by teachers in developing early childhood languages at kindergarten Ismaria Rajabasa Bandar Lampung. Then authors formulated the title of the study of the effectiveness of the question and answer method in developing early childhood language at kindergarten Ismaria Rajabasa Bandar Lampung.

The formulation of the problem in this study is "how is the effectiveness of the question and answer method in developing early childhood language in Raudhatul Athfal Ismaria Rajabasa Bandar Lampung?". The purpose of this study was to determine the effectiveness of the question and answer method in developing early childhood language at kindergarten Ismaria Rajabasa Bandar Lampung.

In this study the authors used a qualitative descriptive study. Data collection techniques that I use are observation, interviews, and documentation. The steps of the question and answer method that have been applied by the teacher in developing early childhood language at Raudhatul Athfal Ismaria Rajabasa Bandar Lampung include: Preparation phase of question and answer, initial stage of question and answer, stage of question and answer development, final stage of question and answer. By applying the steps of the question and answer method in Raudhatul Athfal Ismaria Rajabasa Bandar Lampung, children's language development can develop properly. Based on the results of this analysis, it can be concluded that the question and answer method has been carried out with good and effective steps in developing early childhood language.
\end{abstract}

Keywords: Question and answer method, early childhood language

\title{
A. PENDAHULUAN
}

Undang-undang Nomor 20 Tahun 2003 tentang Sistem Pendidikan Nasional Pasal 1 angka 14 menyatakan bahwa Pendidikan Anak Usia Dini (PAUD) adalah suatu upaya pembinaan yang ditujukan kepada anak sejak lahir sampai dengan usia enam tahun yang dilakukan melalui pemberian rangsangan pendidikan untuk membantu pertumbuhan dan perkembangan jasmani dan rohani agar anak memiliki kesiapan dalam memasuki pendidikan lebih lanjut (UU SISDIKNAS, 
J-SANAK: Jurnal Kajian Anak

(p-ISSN: 2686-5343 le-ISSN: 2715-7989)

Vol. (1) (2), (Januari - Juni) (2019), (Halaman)(1-14)

DOI: https://doi.org/10.24127/j-sanak.v1i02.126

2011). Pendidikan anak usia dini merupakan pendidikan yang paling mendasar dan menempati kedudukan sebagai golden age dan sangat strategis dalam pengembangan sumber daya manusia.

Maka langkah preventif yang dapat ditempuh oleh pendidik guna mengotimalkan pertumbuhan dan perkembangan anak dalam pembelajaran, salah satunya dengan mnggunakan metode. Dengan adanya metode maka penyampaian dari suatu pembelajaran akan mudah diterima dan dipahami oleh anak. Menurut Moeslichatoen R, metode merupakan bagian dari strategi kegiatan. Metode yang dipilih berdasarkan strategi kegiatan yang sudah dipilih dan ditetapkan. Metode merupakan cara, yang dalam bekerjanya merupakan alat untuk mencapai tujuan kegiatan, (Moeslichatoen R, 2004).

Setiap guru akan menggunakan metode sesuai gaya melaksanakan kegiatan. Namun yang harus di ingat taman kanak-kanak mempunyai cara yang khas. Oleh karena itu metode-metode yang lebih sesuai bagi anak TK dibandingkan dengan metode-metode lain. Misalnya guru menggunakan metode tanya jawab untuk mengembangkan bahasa anak.

Metode tanya jawab mempunyai ciri khas dalam cara penyajian pembelajaran dalam bentuk pertanyaan yang harus dijawab, terutama dari guru kepada siswa, tetapi dapat pula dari siswa kepada guru, (Syaiful Bahri Djamarah dan Aswan Zain, 2010). Menurut Depdikbud dalam Nurbiana Dheini bahwa metode tanya jawab adalah suatu metode dalam pengembangan bahasa yang dapat memberikan rangsangan agar anak aktif untuk berpikir, melalui pertanyaan-pertanyaan guru, anak akan berusaha untuk memahaminya dan menemukan jawabannya. Sedangkan Menurut Soetomo metode tanya jawab adalah suatu metode dimana guru memberikan pertanyaan kepada anak dan anak menjawab. Atau sebaliknya, anak bertanya kepada guru dan guru menjawab (Dheini, 2013).

Dari beberapa pengertian tersebut dapat disimpulkan bahwa metode tanya jawab untuk pengembangan bahasa di TK adalah suatu metode mengembangkan bahasa yang dapat memberikan rangsangan agar anak aktif berpikir. Melalui pertanyaan-pertanyaan guru, anak akan berusaha untuk memahaminya dan menemukan jawabannya, atau menemukan pertanyaan untuk ditanyakan ke gurunya. Dalam metode tanya jawab, guru dan siswa sama-sama aktif. Siswa dituntut untuk aktif agar mereka tidak tergantung pada keaktifan guru (Masitoh dan Laksmi Dewi, 2009).

Menurut Depdikbud dalam Nurbiana Dheini ada beberapa hal yang harus mendapat perhatian dalam pelaksanaan kegiatan tanya jawab sebagai berikut :

1. Pertanyaan hendaknya ditujukan kepada semua anak, sehingga setiap anak merasa dapat diberi kesempatan untuk menjawab pertanyaan

Copyright (C) 2020, Universitas Muhammadiyah Metro| 3 
J-SANAK: Jurnal Kajian Anak

(p-ISSN: 2686-5343 le-ISSN: 2715-7989)

Vol. (1) (2), (Januari - Juni) (2019), (Halaman)(1-14)

DOI: https://doi.org/10.24127/j-sanak.v1i02.126

2. Pertanyaan hendaknya tidak keluar dari ruang lingkup bahan pengembangan yang telah diajarkan

3. Pertanyaan hendaknya mencakup dan mewakili tujuan yang hendak dicapai

4. Guru hendaknya membimbing dan mengarahkan pengamatan atau pemikiran anak terhadap bahan pengembangan yang sedang dipelajari

5. Pertanyaan hendaknya diajukan ketika suasana kelas dalam keadaan tenang dan anak-anak telah menunjukkan kesiapan mental

6. Setiap jawaban anak hendaknya dihargai. Jika jawaban anak salah, guru hendaknya memperbaiki dengan bijaksana

7. Guru hendaknya berusaha membangkitkan keberanian untuk anak bertanya

8. Guru hendaknya memberikan contoh bagaimana cara mengajukan pertanyaan yang baik

9. Sebelum guru menjawab pertanyaan anak, lebih baik jawaban itu ditawarkan kepada semua anak. Jika kemudian ternyata semua anak tidak dapat menjawab maka gurulah yang menjawab

10. Kalimat pertanyaan yang diberikan hendaknya menggunakan bahasa sederhana, singkat dan jelas, (Dheini,2013).

Jadi asumsi sementara yang dapat penulis ambil bahwa apabila peranan guru melalui metode tanya jawab dalam mengembangkan bahasa anak usia dini telah dilaksanakan dengan baik, maka perkembangan bahasa anak akan baik juga. Begitu juga sebaliknya apabila peranan guru melalui metode tanya jawab dalam mengembangkan bahasa anak belum terlaksana dengan maksimal maka anak tidak akan memiliki perkembangan bahasa yang baik.

Sementara itu berdasarkan hasil prasurvey peneliti di kelas B6 RA Ismaria Rajabasa Bandar Lampung. Maka diperoleh suatu data bahwa dimana seorang pendidik dalam mengajar menggunakan metode tanya jawab. Hal ini sebagaimana di ungkapkan oleh seorang pendidik yang bernama ibu Sri Karsumi yang menjelaskan bahwa:

Dalam kegiatan belajar mengajar, saya menggunakan metode tanyan jawab karena metode tanya jawab juga cocok dalam mengembangkan bahasa anak, namun setelah dillaksanakan metode tanya jawab bahasa anak masih kurang atau belum berkembang. Hal ini terlihat dalam keseharian anak disekolah kadang ada anak yang tidak mau berbicara jika ada pertanyaan dari guru atau dalam kegiatan lain, hal ini tentu akan mengahambat perkembangan bahasa anak, (Sri Karsumi wawancara).

Berdasarkan hasil prasurvey diatas peneliti berminat untuk menganalisa sejauh mana efektivitas metode tanya jawab dalam mengembangkan bahasa anak 
J-SANAK: Jurnal Kajian Anak

(p-ISSN: 2686-5343 le-ISSN: 2715-7989)

Vol. (1) (2), (Januari - Juni) (2019), (Halaman)(1-14)

DOI: https://doi.org/10.24127/j-sanak.v1i02.126

usia dini di Raudhatul Athfal Ismaria Rajabasa Bandar Lampung. Ada beberapa indikator perkembangan bahasa anak usia dini yang berusia 4-5 tahun menurut Nurbiana Dheini sebagai berikut:

Tabel 1

Indikator Perkembangan Bahasa Anak Usia Dini

\begin{tabular}{|c|l|}
\hline $\begin{array}{c}\text { Lingkup } \\
\text { Perkembangan }\end{array}$ & \multicolumn{1}{c|}{$\begin{array}{c}\text { Tingkat Pencapaian Perkembangan Bahasa } \\
\text { Anak Usia 4-5 tahun }\end{array}$} \\
\hline Bahasa & $\begin{array}{l}\text { 1. } \begin{array}{l}\text { Berbicara dalam kalimat kompleks } \\
\text { 2. Menggunakan 5-8 kata dalam kalimat }\end{array} \\
\text { 3. Menanyakan dan menjawab apa, mengapa, kapan, } \\
\end{array}$ \\
$\begin{array}{l}\text { 4an dimana } \\
\text { 4enyukai pendapat dan alasan; menggunakan kata } \\
\text { "karena", (Nurbiana Dheini, 2013) }\end{array}$ \\
\hline
\end{tabular}

Adapun gambaran mengenai perkembangan bahasa anak pada Kelas B6 RA Ismaria Rajabasa Bandar Lampung sebagai berikut:

Tabel 2

Perkembangan Bahasa Anak usia 4-5 Pada Kelas B6 Raudhatul Athfal Ismaria Rajabasa Bandar Lampung

\begin{tabular}{|c|l|c|c|c|c|c|}
\hline \multirow{2}{*}{ No } & \multirow{2}{*}{ Nama } & \multicolumn{5}{|c|}{ Indikator Perkembangan } \\
\cline { 3 - 7 } & & $\mathbf{1}$ & $\mathbf{2}$ & $\mathbf{3}$ & $\mathbf{4}$ & Keterangan \\
\hline 1 & Albokori & BB & MB & BB & BB & BB \\
\hline 2 & Alif & BSH & BB & BSH & BSH & BSH \\
\hline 3 & Almira Cardelia Sari & MB & BB & MB & MB & MB \\
\hline 4 & Arya Aditya Pratama & BB & BB & MB & BB & BB \\
\hline 5 & Azkia Alqila Putri & MB & BSH & BB & BSH & BSH \\
\hline 6 & Bagus Satria & BSH & MB & MB & BB & MB \\
\hline 7 & Cahya Kartika Sari & BB & BSH & BB & BSH & MB \\
\hline 8 & Diah Kalila Penan & MB & BB & BB & BB & BB \\
\hline 9 & Dama Sidiq Pangestu & BB & MB & BB & BSH & BB \\
\hline 10 & Ikram Dika Pratama & BSH & BB & BSH & MB & BSH \\
\hline 11 & Isa Rehanda Bowo & BSH & MB & MB & BB & BB \\
\hline 12 & M. Bari Adzaky & BB & MB & BB & MB & BB \\
\hline 13 & M. Nur Bagus Pratama & BB & BB & MB & BB & BB \\
\hline 14 & M. Novan Hazman & MB & MB & BSH & BB & MB \\
\hline 15 & M. Tegar Ardiyansah & BB & BB & BB & MB & BB \\
\hline 16 & M. Yasir & BB & BB & MB & BB & BB \\
\hline 17 & Nabila Syafutri & BB & BSH & BSH & MB & BSH \\
\hline 18 & Naufal Jefri Wilian & MB & BSH & BSH & BB & BSH \\
\hline 19 & Reehana Maheswari S & BB & MB & MB & BSH & MB \\
\hline
\end{tabular}

Copyright (C) 2020, Universitas Muhammadiyah Metro| 5 
J-SANAK: Jurnal Kajian Anak

(p-ISSN: 2686-5343 le-ISSN: 2715-7989)

Vol. (1) (2), (Januari - Juni) (2019), (Halaman)(1-14)

DOI: https://doi.org/10.24127/j-sanak.v1i02.126

\begin{tabular}{|c|l|c|c|c|c|c|}
\hline 20 & Raihan Khairy Azhar & MB & MB & MB & BB & MB \\
\hline 21 & Raka Oby Setiawan & BB & BSH & BB & MB & BB \\
\hline 22 & Safira Apriyanti & MB & BB & MB & BB & MB \\
\hline 23 & Thalita Abid Munta & BB & MB & MB & BSH & MB \\
\hline 24 & Yoza Alfahri & BSH & BSH & BB & MB & BSH \\
\hline 25 & Zahratul Aini A. & MB & MB & BSH & BB & MB \\
\hline
\end{tabular}

Sumber: Hasil Observasi di Raudhatul Athfal Ismaria Rajabasa Bandar lampung Keterangan Angka:

1. Berbicara dalam kalimat kompleks

2. Menggunakan 5-8 kata dalam kalimat

3. Menanyakan dan menjawab apa, mengapa, kapan, dan dimana

4. Menyukai pendapat dan alasan; menggunakan kata "karena"

Keterangan:

BB (Belum Berkembang)

MB (Mulai Berkembang)

BSH (Berkembang Sesuai Harapan)

Tabel 3

Presentase Hasil Prasurvey Perkembangan Bahasa Anak di Raudhatul Athfal Ismaria Rajabasa Bandar Lampung

\begin{tabular}{|c|c|c|c|c|}
\hline \multirow[t]{2}{*}{ No } & \multirow[t]{2}{*}{ Indikator } & \multicolumn{3}{|c|}{ Indikator Penilaian } \\
\hline & & $\begin{array}{c}\text { Belum } \\
\text { Berkembang }\end{array}$ & $\begin{array}{c}\text { Mulai } \\
\text { Berkemban } \\
\mathrm{g}\end{array}$ & $\begin{array}{c}\text { Berkembang } \\
\text { Sesuai } \\
\text { Harapan }\end{array}$ \\
\hline 1 & $\begin{array}{lll}\text { Berbicara dalam kalimat } \\
\text { kompleks }\end{array}$ & $\begin{array}{l}12 \text { Anak } \\
(48 \%)\end{array}$ & $\begin{array}{l}8 \text { Anak } \\
(32 \%)\end{array}$ & $\begin{array}{l}5 \text { Anak } \\
(20 \%)\end{array}$ \\
\hline 2 & $\begin{array}{lcc}\begin{array}{l}\text { Menggunakan } \\
\text { dalam kalimat }\end{array} & 5-8 \quad \text { kata }\end{array}$ & $\begin{array}{l}9 \text { Anak } \\
(36 \%) \\
\end{array}$ & $\begin{array}{l}10 \text { Anak } \\
(40 \%)\end{array}$ & $\begin{array}{l}6 \text { Anak } \\
(24 \%) \\
\end{array}$ \\
\hline 3 & $\begin{array}{l}\text { Menanyakan dan menjawab } \\
\text { apa, mengapa, kapan, dan } \\
\text { dimana }\end{array}$ & $\begin{array}{l}10 \text { Anak } \\
(40 \%)\end{array}$ & $\begin{array}{l}8 \text { Anak } \\
(32 \%)\end{array}$ & $\begin{array}{l}7 \text { Anak } \\
(28 \%)\end{array}$ \\
\hline 4 & $\begin{array}{l}\text { Menyukai pendapat dan } \\
\text { alasan; menggunakan kata } \\
\text { "karena" }\end{array}$ & $\begin{array}{l}13 \text { Anak } \\
(52 \%)\end{array}$ & $\begin{array}{l}7 \text { Anak } \\
(28 \%)\end{array}$ & $\begin{array}{l}6 \text { Anak } \\
(24 \%)\end{array}$ \\
\hline
\end{tabular}

Berdasarkan keterangan tabel diatas, diketahui bahwa perkembangan bahasa anak pada kelas B6 Raudhatul Athfal Ismaria Rajabasa Bandar Lampung masih rendah belum memenuhi standar yang mengacu pada indikator standar tingkat 
J-SANAK: Jurnal Kajian Anak

(p-ISSN: 2686-5343 le-ISSN: 2715-7989)

Vol. (1) (2), (Januari - Juni) (2019), (Halaman)(1-14)

DOI: https://doi.org/10.24127/j-sanak.v1i02.126

pencapaian dan perkembangan yang merupakan penjabaran dari pencapaian perkembangan dan potensi perkembangan peserta didik.

Adapun data mengenai efektivitas metode tanya jawab yang digunakan guru dalam mengembangkan bahasa anak di Raudhatul Athfal Ismaria Rajabasa Bandar lampung, untuk lebih jelas dapat dilihat pada tabel berikut ini:

Tabel 4

Hasil Prasurvey Efektivitas Metode Tanya Jawab dalam Mengembangkan Bahasa Anak Usia Dini di Raudhatul Athfal Ismaria Rajabasa Bandar Lampung

\begin{tabular}{|c|c|c|c|}
\hline \multirow{2}{*}{ No } & \multirow{2}{*}{ Langkah-langkah } & \multicolumn{2}{|c|}{ Keterangan } \\
\hline & & $\mathbf{Y a}$ & Tidak \\
\hline 1 & $\begin{array}{l}\text { Tahap persiapan tanya-jawab } \\
\text { Langkah persipan ini dimaksudkan agar guru selalu } \\
\text { membuat daftar pertanyaan yang akan diajukan } \\
\text { kepada siswa. Pertanyaan hendaknya dirumuskan } \\
\text { berdasarkan tujuan yang ingin dicapai dan karakter } \\
\text { siswa. Selain itu, guru juga sudah memperkirakan } \\
\text { alokasi waktu yang dibutuhkan untuk melaksanakan } \\
\text { metode tanya-jawab. }\end{array}$ & & $\sqrt{ }$ \\
\hline 2 & $\begin{array}{l}\text { Tahap awal tanya jawab } \\
\text { Pada awal pertemuan yang menggunakan metode } \\
\text { tanya jawab, guru diharapkan memberikan penjelasan } \\
\text { atau pengarahan tentang kegiatan yang akan } \\
\text { dilaksanakan. Guru dapat melakukan dengan } \\
\text { memberitahukan tujuan, langkah-langkah kegiatan, } \\
\text { dan penjelasan garis besar isi pelajaran }\end{array}$ & $\sqrt{ }$ & \\
\hline 3 & $\begin{array}{l}\text { Tahap pengembangan tanya jawab } \\
\text { Apabila guru telah memberikan pengarahan pada } \\
\text { tahap awal tanya jawab, maka guru dapat } \\
\text { mengembangkan metode tanya jawab dengan } \\
\text { menempuh berbagai variasi dalam mengajukan } \\
\text { pertanyaan. }\end{array}$ & & $\sqrt{ }$ \\
\hline 4 & $\begin{array}{l}\text { Tahap akhir tanya jawab } \\
\text { Pada tahap akhir pemakaian tanya jawab,guru } \\
\text { bersama para siswa membuat ringkasan isi pelajaran } \\
\text { yang telah disajikan selama tanya jawab. Kegiatan ini } \\
\text { dimaksudkan untuk pemantapan sajian, dan sekaligus } \\
\text { untuk memperoleh umpan balik dari para siswa }\end{array}$ & & $\sqrt{ }$ \\
\hline
\end{tabular}

Sumber: Hasil Observasi 
J-SANAK: Jurnal Kajian Anak

(p-ISSN: 2686-5343 le-ISSN: 2715-7989)

Vol. (1) (2), (Januari - Juni) (2019), (Halaman)(1-14)

DOI: https://doi.org/10.24127/j-sanak.v1i02.126

Berdasarkan tabel diatas, terlihat bahwa efektivitas metode tanya jawab dalam mengembangkan bahasa anak usia dini di Raudhatul Athfal Ismaria Rajabasa Bandar Lampung telah diterapkan oleh guru dan hasilnya sudah mulai baik dalam mengembangkan bahasa anak, dimana langkah-langkah yang digunakan oleh guru mulai menguasai pembelajaran metode tanya jawab sesuai dengan langkah-langkah metode tanya jawab untuk anak prasekolah.

\section{B. METODOLOGI}

Ditinjau dari objeknya, penelitian ini menggunakan jenis penelitian kualitatif, (Sugiyono, 2008:15). Sifat penelitian ini adalah deskriptif kualitaif yaitu penelitian yang bertujuan menggambarkan secara sistematis mengenai fakta-fakta yang ditemukan di lapangan, bersifat verbal, kalimat, fenomena-fenomena, dan tidak berupa angka-angka. Dengan menggunakan pengumpulan data dengan pendekatan wawancara dan observasi serta dokumentasi untuk menghasilkan data kemudian dianalisis setelah data lapangan telah terkumpul.

\section{HASIL PENELITIAN}

\section{Langkah Langkah Analisis Data}

Setelah terkumpulnya semua data, peneliti menggunakan pendekatan berfikir induktif yaitu pemikiran yang berangkat dari fakta-fakta atau peristiwa-peristiwa khusus kemudian dari fakta-fakta yang khusus tersebut ditarik generalisasigeneralisasi yang mempunyai sifat umum. Bentuk tanya jawab yang dipilih pada dasarnya langkah-langkah kegiatannya sama, sesuai dengan rancangan tema dan tujuan maka ditetapkan langka-langkah sebagai berikut:

Langkah pertama, Tahap persiapan tanya-jawab. Langkah persiapan ini dimaksudkan agar guru selalu membuat daftar pertanyaan yang akan diajukan kepada siswa. Pertanyaan hendaknya dirumuskan berdasarkan tujuan yang ingin dicapai dan karakter siswa. Selain itu, guru juga sudah memperkirakan alokasi waktu yang dibutuhkan untuk melaksanakan metode tanya-jawab.

a. Hasil observasi

Guru mempersiapkan tema pembelajaran yang hendak disampaikan kepada anak. Tema yang ditetapkan sesuai dengan tema semester II yaitu tema alam semesta yang telah dijabarkan melalui Rencana Kegiatan Harian (RKH). Pada tahap ini guru tidak membuat daftar pertanyaan karena guru memberikan petanyaan kepada anak secara spontan maupun sesuai dengan pokok bahasan. 
J-SANAK: Jurnal Kajian Anak

(p-ISSN: 2686-5343 le-ISSN: 2715-7989)

Vol. (1) (2), (Januari - Juni) (2019), (Halaman)(1-14)

DOI: https://doi.org/10.24127/j-sanak.v1i02.126

b. Hasil wawancara

Sebelum masuk ke pembelajaran terlebih dahulu guru telah menetapkan tema pembelajaran yang akan disampaikan kepada anak melalui Rencana Kegiata Harian.

Langkah kedua, Tahap awal tanya-jawab. Pada awal pertemuan yang menggunakan metode tanya-jawab, guru diharapkan memberikan penjelasan atau pengarahan tentang kegiatan yang akan dilaksanakan. Guru dapat melakukan dengan memberitahukan tujuan, langkah-langkah kegiatan, dan penjelasan garis besar isi pelajaran.

a. Hasil observasi

Bahwa guru telah menjelaskan dan memberikan pengarahan kepada anak tentang kegiatan yang akan dilaksanakan. Guru menjelaskan tema alam semesta dengan cara memberikan pengertian kepada anak tentang ciptaan-ciptaan Allah dengan tujuan agar anak mengethui apa saja ciptaan Allah. Ketika guru menjelaskan tema kegiatan anak-anak antusias mendengarkan guru berbicara, namun terdapat beberapa anak tidak memperhatikan guru yang sedang berbicara malah sibuk bermain sendiri denagn teman.

b. Hasil wawancara

Guru menjelaskan dan memberikan pengarahan tentang tema yang akan disampaikan kepada anak mengenai tema alam semesta, seperti manusia, tumbuhan, binatang, gunung, langit, bintang, bulan, matahari, pelangi, laut, dan bumi. Agar anak mengetahui bahwa semua itu adalah ciptaan Allah.

Langkah ketiga, Tahap pengembangan tanya-jawab. Apabila guru telah memberikan pengarahan pada tahap awal tanya jawab, maka guru dapat mengembangkan metode tanya jawab dengan menempuh berbagai variasi dalam mengajukan pertanyaan.

a. Hasil observasi

Setelah guru memberikan penjelasan dan pengarahan tentang tema kegiatan kepada anak. Kemudian guru memberikan pertanyaan kepada anak sesuai dengan pengetahuan anak dari penjelasan yang telah guru beikan. Namun ketika guru memberikan pertanyaan kepada anak, anak tidak mau berbicara ketika ada pertanyaan dari guru. 
J-SANAK: Jurnal Kajian Anak

(p-ISSN: 2686-5343 le-ISSN: 2715-7989)

Vol. (1) (2), (Januari - Juni) (2019), (Halaman)(1-14)

DOI: https://doi.org/10.24127/j-sanak.v1i02.126

b. Hasil wawancara

Guru memberikan pertanyaan kepada anak, namun dalam memberikan pertanyaan tersebut anak justru memilih untuk diam tidak mau berbicara, hal ini tentu akan menghambat perkembangan bahasa anak.

Langkah keempat, tahap akhir tanya jawab. Pada tahap akhir pemakaian tanya jawab, guru bersama para siswa membuat ringkasan isi pelajaran yang telah disajikan selama tanya jawab. Kegiatan ini dimaksudkan untuk pemantapan sajian, dan sekaligus untuk memperoleh umpan balik dari para siswa.

a. Hasil observasi

Guru tidak membuat hasil ringkasan dari tanya jawab, namun guru pada akhir kegiatan mengadakan evaluasi terhadap anak melalui pertanyan dalam mengulas pembelajaran yang telah disampaikan pada awal kegiatan dan kegiatan inti. Guru mengadakan evaluasi di akhir kegiatan agar anak bisa mengungkapkan apa yang telah anak dengar ketika guru menyampaikan materi pembelajaran.

b. Hasil wawancara

Guru mengadakan evaluasi di akhir kegiatan melalui pertanyaan dengan tujuan guru mengulas kegiatan yang diadakan pada awal dan kegiatan inti, dimana anak yang memperhatikan guru berbicara maka anak akan mengungkapkan sesuai dengan apa yang telah ia dengar pada saat guru menyampaikan pembeajaran.

Berdasarkan data yang didapat dilapangan, kemudian penulis analisis berdasarkan temuan temuan yang terdapat di lapangan saat melakukan penelitian, bahwa metode tanya jawab yang telah dilakukan oleh guru di Raudhtul Athfal Ismaria Rajabasa Bandar Lampung dengan langkah yang baik dan efektif dalam mengembangkan bahasa anak usia dini.

\section{Pembahasan hasil penelitian}

Usia prasekolah merupakan suatau fase yang sangat penting dan berharga, yang merupakan masa dalam pembentukan dalam priode kehidupan manusia. Masa anak sering dipandang sebagai masa emas (golden age) bagi penyelenggaraan pendidikan. Masa anak merupakan masa yang sangat fundamental bagi perkembangan individu, karena fase ini terjadi peluang yang sangat besar untuk pembentukan dan perkembangan seseorang.

Beberapa perkembangan dasar di TK yang harus ditumbuh kembangkan diantaranya berbagai kemampuan, kecerdasan, bakat, kemampuan fisik, kognitif, bahasa, sosio-emosional, dan spiritual. Dimana tugas guru dan orang tua sebagai 
J-SANAK: Jurnal Kajian Anak

(p-ISSN: 2686-5343 |e-ISSN: 2715-7989)

Vol. (1) (2), (Januari - Juni) (2019), (Halaman)(1-14)

DOI: https://doi.org/10.24127/j-sanak.v1i02.126

fasilitator dalam memberikan motivasi serta ransangan kepada anak agar pertumbuhan dan perkembangan anak lebih optimal.

Salah satu petumbuhan dan perkembangan dasar di Taman Kanak-kanak adalah bahasa. Bahasa merupakan kemampuan untuk berkomunikasi dengan orang lain. Dalam pengertian ini tercakup semua cara untuk berkomunikasi, dimana pikiran dan perasaan dinyatakan dalam bentuk lambang atau simbol untuk mengungkapkan suatu pengertian seperti dengan menggunakan lisan, tulisan, isyarat, bilangan, lukisan, dan mimik muka.

Oleh karena itu bahasa sangat penting bagi seseorang dalam kehidupan sehari-hari terutama bagi anak usia dini. Fungsi bahasa di TK dapat mempermudah bagi anak untuk bisa berinteraksi dan berkomuikasi dengan lingkungan, dimana melalui bahasa anak dapat menyatakan pikiran, perasaan, dan keinginannya.

Dalam pembelajaran di Raudhatul Athfal Ismaria, guru berupaya untuk mengembangkan bahasa anak melalui pengajaran yang telah disesuaikan dengan program atau jadwal yang ditentukan, memberikan pengawasan terhadap kegiatan belajar, selalu mengadakan komunikasi dengan anak dan berusaha menerapkan pembelajaran yang menarik dan menyenangkan dalam setiap kegiatan.

Dalam mengembangkan bahasa anak usia dini seorang guru menggunakan berbagai metode pembelajaran salah satunya adalah metode tanya jawab. Dimana dalam metode tanya jawab ini anak diberikan motivasi serta ransangan agar anak aktif dalam berikir.

Sebelum kegiatan pembelajaran dilaksanakan terlebih dahulu guru sudah mempersiapkan Rancangan Kegitan Harian (RKH) sebagai berikut:

a) Kegiatan Awal

1) Guru membuka pelajaran dengan salam

2) Guru memimpin doa sebelum kegiatan

3) Guru mengadakan tanya jawab tentang kabar

4) Guru mengambsen kehadiran anak

5) Bernyanyi

b) Kegiatan Inti

1) Bercakap-cakap tentang tema "alam semesta"

2) Guru memperlihatkan gambar-gambar mengenai tema "alam semesta"

3) Guru memberikan pertanyaan kepada anak mengenai ciptaan-ciptaan Allah

4) Anak diberikan tugas membias pola "gunung" 
J-SANAK: Jurnal Kajian Anak

(p-ISSN: 2686-5343 le-ISSN: 2715-7989)

Vol. (1) (2), (Januari - Juni) (2019), (Halaman)(1-14)

DOI: https://doi.org/10.24127/j-sanak.v1i02.126

c) Istirahat

1) Anak mencuci tangan, berdoa, dan makan bersama

2) Bermain diluar kelas

d) Kegiatan Akhir

1) Evaluasi

2) Doa pulang dan salam

Pada kegiatan pembelajaran guru melaksanakan pembelajaran sesuai dengan Rancangan Kegiatan Harian (RKH) yang telah dipersiapkan sebelum kegiatan pembelajaran dilaksanakan. Rencana kegiatan harian terdiri dari kegiatan awal, kegiatan inti, istirahat, dan kegiatan akhir. Hal ini selaku guru atau tenaga pengajar Raudhatul Athfal, Sri Karsumi menyatakan bahwa: dalam usaha mengembangkan bahasa anak, kami selalu berusaha melaksanakan dengan maksud agar perkembangan bahasa atau komunikasi anak dapat menjadi lebih baik.

Selanjutnya Guru atau tenaga pengajar di Raudhatul Athfal Ismaria mengemukakan bahwa: kami sudah berusaha untuk meningkatkan keaktifan anak dalam pembelajaran dengan memberikan motivasi serta nasihat, memberi pengawasan pada saat proses belajar, menghargai pendapat dan kemajuan yang ditingkatkan dengan memberikan pujian, dengan hal-hal tersebut anak menjadi berani dan senang dengan apa yang diberikan oleh guru.

Jadi dari hasil observasi dan wawancara di Raudhatul Athfal Ismaria Rajabasa Bandar Lampung dapat disimpulkan bahwa, guru dalam mengembangkan bahasa anak selalu mengadakan komunikasi dengan anak, sudah berusaha untuk meningkatkan keaktifan anak dalam pembelajaran dengan memberikan motivasi serta nasihat, memberi pengawasan pada saat proses belajar, menghargai pendapat dan kemajuan yang ditingkatkan dengan memberikan pujian, dengan hal-hal tersebut anak menjadi berani dan senang dengan apa yang diberikan oleh guru.

Dari hasil wawancara kepada bu Sri Karsumi bahwa metode tanya jawab sudah diterapkan, namun dalam penerapan metode ini sering mengalami kendalakendala dimana ketika guru memberikan pertanyaan kadang ada anak tidak mau berbica dan ada juga anak tidak memperhatikan guru yang sedang berbicara, hal ini terlihat anak yang sibuk bermain dengan temannya.

Jadi dapat disimpulkan bahwa kendala yang sering dihadapi oleh guru ketika melaksanakan metode tanya jawab kadang ada anak yang tidak mau berbicara ketika ditanya dan ada juga anak tidak memperhatikan guru yang sedang 
J-SANAK: Jurnal Kajian Anak

(p-ISSN: 2686-5343 le-ISSN: 2715-7989)

Vol. (1) (2), (Januari - Juni) (2019), (Halaman)(1-14)

DOI: https://doi.org/10.24127/j-sanak.v1i02.126

berbicara, malah anak sibuk bermain dengan temannya. Hal ini tentunya akan menghambat perkembangan bahasa anak.

\section{DAFTAR PUSTAKA}

Abdul Chaer.(2009). Psikolinguistik. Jakarta: Rineka Cipta.

Abdul Mujib dan Jusuf Mudzakkir. (2010), Ilmu Pendidikan Islam. Jakarta: Kencana Prenada Media.

Ahmad Munjin Nasih dan Lilik Nur Kholida. (2009). Metode dan Teknik Pembelajaran Pendidikan Agama Islam. Bandung: PT Refika Aditama.

Ahmad Susanto. (2012). Perkembangan Anak Usia Dini. Jakarta: Kencana PrenadaMedia

Group.

Cholid Narbuka dan Abu Achmadi. (2012). Metode Penelitian, Jakarta: PT Bumi Aksara,

Cetakan ke 12.

Departemen Pendidikan Nasional. (2001). Kamus Besar Bahasa Indonesia. Jakarta: Balai

Putaka.

Desmita. (2009). Psikologi Perkembangan. Bandung: PT Remaja Rosdakarya.

Djawad Dahlan. (2009). Psikologi Perkembangan Anak dan Remaja. Bandung:

Remaja Rosdakarya.

Elizabeth B. Hurlock. (1978). Perkembangan Anak. Jakarta: Erlangga, Edisi Keenam.

Hakam Abbas. (2011). "Metode Tanya Jawab" (On-line), tersedia di: http://hakamabbas.blogspot.com/2013/10/metode-tanya-jawab-30.html?m=1

Hamdani. Strategi Belajar Mengajar. Bandung: Pustaka Setia.

Iskandarwassid dan Dadang Sunendar. (2008). Strategi pembelajaran Bahasa. Bandung:PT Remaja Rosdakarya.

John W. Santrock. (2007). Perkembangan Anak . Jakarta: Erlangga.

Martinis Yamin, dan Jamilah Sabri Sanan. (2013). Panduan PAUD. Jakarta:

Gaung Persada

Press Group.

Masitoh dan Laksmi Dewi. (2009). Strategi Pembelajaran. Jakarta: Departemen Agama

Republik Indonesia.

Masitoh, dkk. (2011). Strategi Pembelajaran TK. Jakarta: Universitas terbuka, cetakan

Pertama.

Nurbiana Dheini. (2011). Metode Pengembangan Bahasa. Jakarta: Universitas Terbuka, Cetakan Pertama.

Penney Upton. (2012). Psikologi Perkembangan. Jakarta: Erlangga. 
J-SANAK: Jurnal Kajian Anak

(p-ISSN: 2686-5343 le-ISSN: 2715-7989)

Vol. (1) (2), (Januari - Juni) (2019), (Halaman)(1-14)

DOI: https://doi.org/10.24127/j-sanak.v1i02.126

Rini hildayani. (2007). Psikologi Perkembangan Anak. Jakarta: Universitas Terbuka.

Roestiyah. (2008). Strategi Belajar Mengajar.Jakarta: Rineka Cipta.

Sugiyono. (2008). Metode Penelitian Pendidikan (Pendekatan Kuantitatif, kualitatif, dan R\&D). Bandung: Alfabeta.

Syaiful Bahri Djamarah dan Aswan Zain. (2010). Strategi Belajar Mengajar. Jakarta: Rineka Cipta.

Syaiful Sagala. (2013). Konsep dan Makna Pembelajaran. Bandung: Alfabeta.

Undang-undang SISDIKNAS Sistem Pendidikan Nasional. (2011). Jakarta: Sinar Grafika.

Wayan Aprina Dewi, dkk. "Penerapan Metode Tanya Jawab" (On-line), tersedia di:

http://ejournal.undiksha.ac.id/index.php/JJPAUD/article/download/3217/2 673

Yudrik Jahja. (2013). Psikologi Perkembangan. Jakarta: kencana, cetakan pertama.

Zulkifli. (2005). Psikologi Perkembangan. Bandung: Remaja Rosdakarya. 